Article

\title{
Impact of Stationary and Dynamic Conditions on the U-Value Measurements of Heavy-Multi Leaf Walls by Quantitative IRT
}

\author{
Blanca Tejedor ${ }^{1, *(\mathbb{D}}$, Eva Barreira ${ }^{2}{ }^{\mathbb{D}}$, Vasco Peixoto de Freitas ${ }^{2}$, Tomasz Kisilewicz ${ }^{3}$, \\ Katarzyna Nowak-Dzieszko ${ }^{3}$ and Umberto Berardi 4 (D) \\ 1 Group of Construction Research and Innovation (GRIC), Department of Project and Construction \\ Engineering, Universitat Politècnica de Catalunya (UPC), C/Colom, 11, Ed. TR5, 08222 Terrassa, Spain \\ 2 Department of Civil Engineering, CONSTRUCT-LFC, Faculty of Engineering (FEUP), University of Porto, \\ Rua Dr. Roberto Frias, 4200-465 Porto, Portugal; barreira@fe.up.pt (E.B.); vpfreita@fe.up.pt (V.P.d.F.) \\ 3 Department of Building Design and Building Physics, Faculty of Civil Engineering, \\ Cracow University of Technology, 31-155 Cracow, Poland; tkisilew@pk.edu.pl (T.K.); \\ knowak-dzieszko@pk.edu.pl (K.N.-D.) \\ 4 Department of Architectural Science, Ryerson University, Toronto, ON M5B 2K3, Canada; \\ uberardi@ryerson.ca \\ * Correspondence: blanca.tejedor@upc.edu; Tel.: +34-93-7398919
}

Received: 7 November 2020; Accepted: 13 December 2020; Published: 15 December 2020

\begin{abstract}
Infrared thermography (IRT) has become a commonly applied non-destructive testing method for assessing building envelopes. Like any diagnosis tool, IRT requires an appropriate experience and principle understanding, mainly when the method is used for quantitative analyses. The challenges of the IRT often deal with the dynamic properties of building partitions. Climatic conditions have a certain variability, and the accumulated energy storage in the building components can affect their temperature as well as the calculated thermal performance. This paper aims to analyze how stationary and dynamic regimes of a quantitative IRT test could impact the measured thermal transmittance of heavy multi-leaf walls. Investigation in two European countries with different climatic conditions are reported. In this way, it is discussed which boundary conditions should be guaranteed to provide reliable information about a building envelope using quantitative IRT. In order to check the quality of the measurements, the heat flux meter (HFM) method was also implemented, following the ISO 9869. The research revealed that it could be possible to use short-lasting tests in the climatic conditions of Southern Europe, while long-term tests should be implemented in Northern European countries where climatic conditions are less regular.
\end{abstract}

Keywords: thermal transmittance; heat flux meter (HFM); quantitative infrared thermography (QIRT); climatic chamber; in situ measurements; stationary conditions; dynamic conditions

\section{Introduction}

The increment of building energy consumption and the respective sensibility of police makers to energy conservation are leading the request for a proper design and accurate assessment of the construction elements [1]. Along this line, Evola et al. [2] pointed out that the enhancement of the indoor thermal comfort and the increase of energy savings of a building are related to the thermal insulation of the envelope as well as ventilation strategies. In the last decade, non-destructive testing techniques such as the heat flux method (HFM) and the quantitative thermography (QIRT) have become an essential tool to characterize walls and facilitate the decision-making of practitioners. In addition to this, a significant reduction of the prices of infrared thermal cameras has allowed to increase the 
number of users [3]. Easier access to infrared equipment and a greater need for researching building performance assessment may not go hand in hand without a complete understanding of the rules and limitations associated with this technique. In other words, the ease of making measurements may encourage rough interpretations of thermal images and imply significant diagnostic errors. Generally, the infrared method has been widely used for the detection of defects in buildings in a qualitative way, following regulations such as ASTM C 1060-90 [4], ISO 6781-3:2005 [5], and UNE EN 13187:1998 [6]. Recently, the standard ISO 9869-2: 2018 [7] introduced the possibility of using the infrared camera for quantitative assessments of the façade, but only in the case of lightweight frame structures with a daily thermal capacity below $30 \mathrm{~kJ} /\left(\mathrm{m}^{2} \mathrm{~K}\right)$. This research aims to investigate the impact of the stationary and dynamic conditions on the measured thermal transmittance of well-insulated heavy walls by heat flux meter and quantitative infrared thermography.

This paper is structured in five parts. Section 2 presents the drawbacks related to the HFM and QIRT measurements under stationary and dynamic conditions (i.e., the required temperature gradient between environments, heat transfer algorithms and the test duration). Section 3 explains the methodology adopted in two measurement campaigns: the first one took place in a climatic chamber of the University of Porto (Portugal), to illustrate the usability of the QIRT in the calculation of the U-value of a representative wall of Southern European countries under stationary regime; the second experimental campaign was conducted on a detached house of Poland, to evaluate how an extreme climate could lead to determine the U-value in transient regime. In Section 4, the outcomes of the laboratory and the real built environment are discussed. To sum up, Section 5 shows the main conclusions of this research.

\section{Background: Thermal Diagnosis of Building Components}

\subsection{Assessment of the U-Value Using the HFM}

Nowadays, the most popular non-invasive technique for assessing the thermal transmittance of building elements is the HFM method, based on the standard ISO 9869-1:2014 [8]. This regulation establishes that the test duration should be an integer multiple of $24 \mathrm{~h}$. The minimum sampling duration is set at $72 \mathrm{~h}$ for homogenous walls and one week for heterogeneous walls. However, the assessment of light components is limited to night hours. The same standard also highlights that the test shall be stopped when: (i) the deviation between the R-value at the end of the test and the R-value obtained $24 \mathrm{~h}$ earlier is not more than $\pm 5 \%$; (ii) the fluctuation in heat stored is estimated to be $<5 \%$ of the heat transferred across the element over the period of analysis [8,9].

Kisilewicz [10] described the results of HFM laboratory tests of a wall under quasi-periodic temperature changes. The reference $\mathrm{R}$-value of a wall with two-layers, previously tested in steady-state conditions, was equal to $2.68 \mathrm{~m}^{2} \cdot \mathrm{K} / \mathrm{W}$. The aggregated mean thermal resistance value for one full cycle of changes $(24 \mathrm{~h})$ was equal to $2.89 \mathrm{~m}^{2} \cdot \mathrm{K} / \mathrm{W}$. This led to obtain a value $6.3 \%$ higher than the stationary value. An extension of the considered period for two full cycles only improved this result to $6.1 \%$, while the calculation period for three full cycles did not change the mentioned result. The obtained difference of results was close to the measuring error of the applied system. Therefore, correct results can be obtained, even under conditions of significant temperature fluctuations. However, the length of the measurement period and the often-emphasized integer number of periods are important. In the real built environment, only ex post allows determining the test conditions and the necessary calculation period. Thus, a sufficiently long period of measurements is required in order to select the appropriate part for calculations. The basic $24 \mathrm{~h}$ data collection period is related to the periodic daily fluctuation in external environments. Such pattern is the basis for analytical dynamic modelling of building components by means of harmonic thermal waves in accordance with the standard EN 13786:2017 [11]. Due to the quasi-sinusoidal fluctuations of environmental conditions in Poland, the algorithm in harmonic conditions is widely applied to 
compute the transient characteristics of walls [8]. In this approach, a building element is characterized by the so-called structural coefficients [12].

Evangelisti et al. [13] evaluated different approaches used for calculating the convective heat transfer coefficients and their impact on the thermal transmittance measured from outside the building. In this way, it was also possible to analyze the applicability of UNE EN ISO 6946 [14]. Subsequently, Evangelisti et al. [15] analyzed the impact of heating systems on different types of U-value assessments (simulation model, on-site measurements using HFM and post-processing method based on linear trendline). They concluded that the implementation of the linear trendline method could reduce the effect of the disturbances of heating systems in the post-processed thermal transmittance, especially in residential buildings.

Gaspar et al. [9] carried out a comparative analysis about the use of dynamic and average method in the post-processing of HFM measurements in the Mediterranean Climate. The study revealed that only the dynamic method can provide reliable results if the temperature gradient across the building envelope is low. Along this line, Atsonios et al. [16] pointed out that the main drawbacks of standardized methods such as the HFM were the test duration and the dependency of the outcomes on the boundary conditions. In fact, a higher thermal gradient between the hot and cold wall surface should be required for short-lasting tests. The authors also mentioned that the results could present low dispersion whether heat flux direction was practically constant during the monitoring.

Marino et al. [17] demonstrated that dynamic response can be treated as negligible in the case of double pane windows and significant in case of heavy multi-leaf walls $\left(0.30-0.45 \mathrm{~W} / \mathrm{m}^{2} \cdot \mathrm{K}\right)$ of Italy. To minimize this effect, they suggested to conduct consecutive measurements early in the morning and at night under quasi-steady conditions. Along this line, Kisilewicz [18] also demonstrated that $R$-value of a concrete wall was $59 \%$ higher than the reference value in stationary conditions. This was due to the overestimation of the wall resistance resulting from the large amount of energy stored in it. The one-way temperature change of the heavy multi-leaf wall was compensated by the internal energy of this partition. In the case of the wall with low thermal capacity, $R$-value was $4.9 \%$ lower than the reference stationary value. The authors concluded that the simplest calculations could be only suitable for a low heat capacity component, as the use of structural coefficients did not enhance the precision of the outcomes obtained for the concrete wall.

Lucchi et al. [19] proposed an experimental procedure to evaluate non-homogeneous walls using a climatic chamber in Italy. Qualitative IRT survey, gravimetric tests, HFM measurements as well as simulation in stationary and transient regime were carried out. Lucchi et al. [19] affirmed that HFM results of lightweight walls or inhomogeneous walls could present low reliability. For this reason, the enhancement of the accuracy should consider extending the metering section, to pre-condition the mock-up in the climatic chamber at least $24 \mathrm{~h}$, to apply highly insulating materials to traditional walls and to augment the temperature difference between cold and hot chambers among other aspects.

\subsection{Assessment of the U-Value Using the Quantitative IRT}

Regarding infrared thermography, no standards exist to define procedures to assess the in situ U-value of building components [20]. For this reason, several authors have developed research work on this topic, allowing stablishing criteria to perform the tests and the calculation procedures [20-26]. Based on this, two different approaches can be found in the literature: thermal diagnostic of building components under static conditions and thermal diagnostic of building components under dynamic conditions.

\subsubsection{Quantitative Infrared Thermography under Steady-State Conditions}

Fokaides et al. [22] presented one of the basic reviews on this topic. They identified the most significant parameters of measurements, conducted sensitivity analysis, and discussed in detail the possible sources of error. They found that the expected $20 \%$ deviation between the notional U-value and 
infrared testing resulted acceptable. However, Fokaides et al. [22] suggested that infrared testing can be more accurate than the other methods due to the fact that the radiative heat transfer was considered.

Asdrubali et al. [27] presented a new method of infrared quantitative testing of thermal bridges that allowed to specify linear thermal transmittance values. The authors suggested an acquisition time of at least three days, to obtain an asymptotic line with an average value of instantaneous measurements that was better adjusted to notional U-value. Long term external infrared tests were performed with the aim of checking the usability of this technique for determining the thermal transmittance of walls. Six specimens with different assemblies (including material layers and structures) were tested using identical boundary conditions in southern Europe. The authors conducted an analysis of sensitivity of the most significant parameters in the measurements and stated that $\mathrm{T}_{\mathrm{OUT}}$ and $\mathrm{T}_{\text {WALL }}$ are the ones with highest impact on the precision of the method. They have also pointed a set of conditions required for carrying out infrared testing: stable weather conditions before testing (for $24 \mathrm{~h}$ ) with a temperature swing less than $6^{\circ} \mathrm{C}$, temperature difference of at least $15^{\circ} \mathrm{C}$, early morning measurements and overcast sky, wind speed $<0.5 \mathrm{~m} / \mathrm{s}$. They demonstrated good repeatability of the proposed methodology for heavy multi-leaf walls while the results could be less reliable in the case of lightweight walls. Typically, the minimum thermal gradient was set at $10^{\circ} \mathrm{C}$. Along this line, Ficco et al. [28] corroborated this aspect. They stated that a temperature difference $<10^{\circ} \mathrm{C}$ and the resulting heat flux could imply inadmissible uncertainties. Furthermore, they recommended to extend the sampling period to $120 \mathrm{~h}$ in order to obtain higher reliability.

Nardi et al. [29] compared quantitative IRT and HFM measurements to validate the reliability of the external thermography for the estimation of the U-value using a hot box apparatus. This study also allowed to overcome some weaknesses of the QIRT. The maximum deviation percentage between these two non-invasive techniques was $12.9 \%$. Within this context, Nardi et al. [30] analyzed the applicability of quantitative external thermography for walls with different age, assembly of material layers, and construction type (historical building, private house, and public building). The authors suggested a set of recommendations related to weather conditions and repeatability of IRT tests. Nardi et al. [31] assessed the U-value of a wall by HFM measurements, theoretical calculations, and four infrared methods. The measurements were conducted in a laboratory with Hot Box method in a controlled environment under different operative conditions. The tests confirmed the usability of the quantitative infrared testing and specific applied methods, with uncertainties ranging between 5 and 10\%. The same authors also drawn up a very extensive critical literature review on quantitative infrared testing [1]. They emphasized the advantages of this technique: short measurement time, reduced costs, and possibility to cover big parts of building external envelope. Nevertheless, they also enumerated factors that may affect measurement accuracy, such as the variability of external boundary conditions, surface heat transfer coefficient and minimum required temperature difference. The authors emphasized the impact of the temperature difference and reflected temperature on the measurements precision.

Tejedor et al. [20] presented a quantitative IRT method from inside the building that allowed to estimate the thermal transmittance in a short period of time, specifically in $2-3 \mathrm{~h}$. In this method, $\mathrm{T}_{\mathrm{WALL}}$ and $\mathrm{T}_{\mathrm{REF}}$ were recorded by means of an infrared camera, while environmental conditions were collected with thermocouples. Heat transfer on the internal surface, divided into heat flux exchanged by convection and radiation, was computed according to a detailed algorithm. In this way, the U-value was calculated as the average of instantaneous measurements. The validation of this method consisted of the comparison of the in situ measurements with the design nominal data. The investigated façades were two walls (single-leaf wall and multi-leaf wall) under different boundary conditions. Indeed, the thermal gradient through the wall was within the range of $7-10{ }^{\circ} \mathrm{C}$ in the case of test without heating. The deviation between the theoretical and measured $\mathrm{U}$-value was 1.24 up to $3.97 \%$ for a test duration of $2-3 \mathrm{~h}$. Further research of the same authors allowed evaluating the impact of operating conditions and thermo-physical properties on the quality of the results [32] as well as verifying if non-transient regime have been achieved during in situ tests [33]. The results pointed out that the most 
favorable range of temperature gradient between inside and outside environment was from 7 to $16^{\circ} \mathrm{C}$, considering unheated buildings and heavy and poorly insulated walls. In addition, they stated that a stochastic analysis could help to reduce the sampling period and only $30 \mathrm{~min}$ could be enough for homogeneous specimens. Recently, the authors developed a 2D U-value map to automatically evaluate entire walls pixel-by-pixel under the impact of anomalies using quantitative IRT [34]. The results were checked by HFM method. This approach allowed to diminish the complexity, the computation time, and the infrastructure costs. Usual methodologies implemented a sensor network that contained between 21 and 35 sensors for heterogeneous specimens [19,35].

Lucchi [36] characterized several historic stone masonries through several methodologies, such as gravimetric tests, visual inspections, and infrared thermography among others. She mentioned that the tabulated design method from standard procedures overestimate the thermal transmittances in comparison with in situ tests, especially walls of heritage buildings. Her study also demonstrated that the void percentage is less in historical buildings than conventional buildings. Lucchi [3] performed a critical review about the applications of thermography in building energy audits. She underlined some aspects: (i) IRT combined with simulation can help to check the gap between nominal data and as-built thermal performance; (ii) long-lasting IRT surveys are normally executed for characterize walls under transient regime, especially for evaluating the variation of solar irradiance; (iii) short-term campaigns are more used, but they could require to fulfill more boundary conditions in order to obtain a good accuracy and reliable data (i.e., stable weather conditions and environmental indoor conditions, no rainy and sunny days, average wind speed $<1 \mathrm{~m} / \mathrm{s}$, use of high thermal gradient between inside and outside the building for walls with low U-value etc.).

\subsubsection{Quantitative Infrared Thermography under Dynamic Conditions}

Boundary conditions have a relevant impact on the outcomes of experimental tests of the U-value and consequently, they could influence in the selection of the measurement method. It has already been mentioned earlier, the duration of the measurements can depend on the wall assembly (i.e., the heat capacity of the partition tested) and the higher daily variability of the external climate. It is also well-known that favorable test conditions are given by a cloudy sky period, low intensity of solar radiation, and a small amplitude of changes of the outside air temperature [3,23].

Quantitative measurements of a building component thermal resistance inside a climatic chamber by means of thermal imaging were reported in Kisilewicz et al. [18]. The wall had two layers: the silica structural brickwork and ETICS system Ambient air temperatures and wall surface temperatures were simultaneously recorded using T-type thermocouples and IR camera. To assess air temperature, a paper sheet was mounted on the tripod within the FOV and $0.30 \mathrm{~m}$ away from the tested wall. Due to the differential measurement method, the systematic reading error was eliminated. Thermograms were taken with a data acquisition interval of $30 \mathrm{~min}$. The results were validated through the common standardized method, the HFM. The authors stated that the major physical problem associated with this type of measurement was related to the heat transfer at the surface of the building façade, since moderate forced convection was detected in the warm side of the climatic chamber.

Dall'O et al. [23] described the results of external testing of building walls as a method of quick thermal diagnostics, useful for energy audit of buildings. The measurements were conducted on 14 buildings with a two-day testing period. The authors concluded that infrared tests gave correct results for poorly insulated walls, while a greater discrepancy was obtained for externally insulated components.

Extensive studies on the impact of external climatic conditions on the results of infrared testing were performed by Lehman et al. [37]. The authors aimed determining the most significant climatic parameters needed to correctly interpret the thermal images. Depending on the wall type, the sensitivity to changes attributed to external boundary conditions and the time of extinction of the impulse were determined. For walls with external insulation (ETICS system), extinction time was usually quite short $(1 \mathrm{~h})$, even the deviation was lower than the relevance criterion. In the case of a concrete 
layer, this time could be extended up to $45 \mathrm{~h}$. Nevertheless, the sensitivity of the walls to moderate temperature changes (up to $8^{\circ} \mathrm{C}$ ) was low, regardless of the wall type.

Danielski et al. [38] carried out IRT and HFM measurements in natural non-stationary conditions. Their purpose was to demonstrate that it was possible to obtain reliable thermal performance data using a larger number of instantaneous values. The investigated sample consisted of a thick laminated timber wall. The authors confirmed the usability of quantitative thermography for computing the U-value of walls under non stationary conditions, since the deviation between the HFM and IRT measurements was found to be $4 \%$. Notably, the wall was exposed to the high variability of external conditions of Sweden, since outer ambient air temperatures ranged between $-19^{\circ} \mathrm{C}$ and $7{ }^{\circ} \mathrm{C}$. This implied to observe a large disparity among the instantaneous measurements of the HFM respect to the expected value. Aversa et al. [39] also developed a method to evaluate the thermal performance of building components under dynamic conditions. The authors highlighted that the indoor temperature should be constant during the test, the monitoring process should be conducted by two IR cameras, and the periodic square wave signal for three cycles should be applied.

\section{Materials and Methods}

\subsection{Laboratory Testing under Steady-State Conditions}

To analyze a representative façade of southern European countries, a well-insulated heavy multi-leaf wall was assembled in a climatic chamber of University of Porto during April 2019 (Figure 1). The internal configuration of the mock-up was (from outside to inside): lightweight concrete $(0.25 \mathrm{~m})$, lightweight mortar $(0.01 \mathrm{~m})$, EPS $(0.06 \mathrm{~m})$ and plasterboard $(0.015 \mathrm{~m})$. The stratigraphy and thermo-physical properties of each material layer are detailed in Table 1. It should be pointed out that the climatic chamber comprised three resistances, one compressor, two fans, several sensors, and a display where the technician configured the boundary conditions (temperature and humidity) that were required for the internal QIRT tests. Based on this, the ambient air temperature inside the climatic chamber was $35^{\circ} \mathrm{C}$ and the outer ambient air temperature was by default $18-20^{\circ} \mathrm{C}$. For all measurements, the wall was pre-conditioned at least $72 \mathrm{~h}$ to guarantee constant conditions. Furthermore, to avoid unknown reflection indexes or possible disturbances during the QIRT measurements, a black cardboard was used to cover the internal surfaces of the climatic chamber.
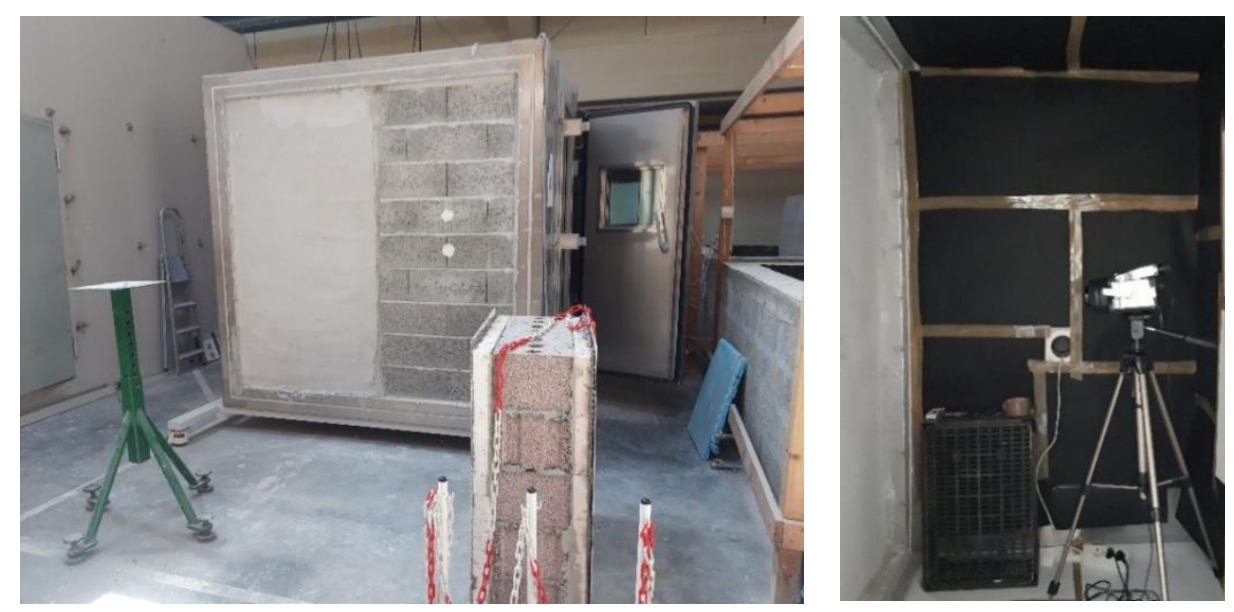

Figure 1. Experimental set-up (outside and inside the climatic chamber). 
Table 1. Thermo-physical properties of an experimental mock-up in Portugal.

\begin{tabular}{|c|c|c|c|c|c|c|c|}
\hline & N\# & $\begin{array}{c}\text { Material } \\
\text { Layer }\end{array}$ & $\begin{array}{l}\Delta \mathrm{x}_{\mathrm{i}} \\
(\mathrm{m})\end{array}$ & $\begin{array}{c}\lambda_{\mathrm{i}} \\
(\mathrm{W} /(\mathrm{m} \cdot \mathrm{K}))\end{array}$ & $\begin{array}{c}\mathrm{R}_{\mathrm{ti}} \\
\left(\left(\mathrm{m}^{2} \cdot \mathrm{K}\right) / \mathrm{W}\right)\end{array}$ & $\begin{array}{c}\mathrm{L} \\
(\mathrm{m})\end{array}$ & $\begin{array}{c}U_{t} \\
\left(W /\left(m^{2} \cdot K\right)\right)\end{array}$ \\
\hline \multirow{4}{*}{$\begin{array}{l}\text { Mock-up } \\
\text { Laboratory } \\
\text { (Portugal) }\end{array}$} & 1 & Lightweight concrete & 0.250 & & \multirow{4}{*}{1.360} & \multirow{4}{*}{1.90} & \multirow{4}{*}{0.313} \\
\hline & 2 & Lightweight mortar & 0.010 & 0.610 & & & \\
\hline & 3 & Insulation EPS & 0.060 & 0.037 & & & \\
\hline & 4 & Plasterboard & 0.005 & & & & \\
\hline
\end{tabular}

UNE EN ISO 10456:2012 [40] and UNE EN ISO 6946:2012 [14] were used to calculate Ut.

For the assessment of the full scale wall under stationary conditions, two non-destructive testing techniques (NDT) were used: Quantitative Infrared Thermography (QIRT) and Heat Flux Meter (HFM). The main specifications of both measuring equipment are shown in Table 2. The first NDT technique was carried out according to the procedure extensively reported by Tejedor et al. [20], which considers a 1D horizontal heat flux generated by convection and radiation processes under stationary regime. For the real built environment, the recommendations of Tejedor et al. [33] and Tejedor et al. [34] should be taken into account in terms of operating conditions, thermo-physical properties and test duration. For example, $30 \mathrm{~min}$ can be enough for homogeneous samples, while 2-3 h are needed for heterogeneous samples. The HFM method was performed following the ISO 9869-1:2014 [8], which assumes the heat flux due to conduction in a steady-state conditions to determine the thermal transmittance.

Table 2. Measuring equipment for both non-destructive testing techniques (NDT) techniques (heat flux meter (HFM) and quantitative infrared thermography (QIRT).

\begin{tabular}{|c|c|c|c|}
\hline Equipment & Operative Range & Resolution & Precision \\
\hline Climatic Chamber & Temperature: $-50{ }^{\circ} \mathrm{C}$ to $180{ }^{\circ} \mathrm{C}$ & 0.1 & $\pm 0.5^{\circ} \mathrm{C}$ \\
\hline Heat flux sensor & $\begin{array}{c}\text { Maximum temperature: } 90^{\circ} \mathrm{C} \\
\text { Temperature correction: }+0.10 \% / \mathrm{K} \\
\text { Thermal conductivity: } 0.25 \mathrm{~W} /(\mathrm{m} \cdot \mathrm{K}) \\
\text { Internal electrical resistance: } 445-450 \mathrm{Ohm} \\
\text { Constant of calibration: } 17\end{array}$ & - & $\pm 5 \%$ \\
\hline IR camera & $\begin{array}{l}\text { Temperature: }-20^{\circ} \mathrm{C} \text { to }+100{ }^{\circ} \mathrm{C} \\
\text { FOV: } 21.7^{\circ} \times 16.4^{\circ} \\
\text { Thermal sensitivity: } 0.04{ }^{\circ} \mathrm{C} \text { at } 30^{\circ} \mathrm{C}\end{array}$ & $320 \times 240$ pixels & $\pm 2{ }^{\circ} \mathrm{C}$ or $\pm 2 \%$ reading \\
\hline T sensors & Temperature: $-20^{\circ} \mathrm{C}$ to $70^{\circ} \mathrm{C}$ & $0.024^{\circ} \mathrm{C}$ & $\pm 0.21^{\circ} \mathrm{C}$ \\
\hline Emissometer & - & - & \pm 0.01 \\
\hline
\end{tabular}

The thermographic monitoring of the heavy multi-leaf wall was performed by an IR camera (NEC TH9100MR) to determine the reflected ambient temperature $\left(T_{R E F}\right)$ and the wall surface temperature $\left(T_{W A L L}\right)$, an emissometer (D\&S, Model AE1) to measure the wall surface emissivity $\left(\varepsilon_{\text {WALL }}=0.93\right)$, and two temperature sensors (HOBO UX100) to record environmental test conditions from inside and outside the climatic chamber $\left(T_{I N}, R H_{I N}, T_{O U T}, R H_{O U T}\right)$. Notably, the emissometer consisted of a detector that was electrically heated in-prior and established a linearity of the output voltage with the emittance of the material (Figure 2). As regards the data acquisition, the test duration for was $2 \mathrm{~h}$, with a sampling frequency of $1 \mathrm{~min}$. This led to assess a total of 121 thermograms per test. Concerning the data post-processing, the technician read and updated $T_{R E F}$ in each thermogram through the IR camera software (InfReC Analyzer [41]), to obtain a reliable value of $T_{W A L L}$. Otherwise, the software took the initial reflected ambient temperature for the entire test by default, without compensating the errors of each instantaneous reading if indoor environmental conditions changed. Having analyzed all thermograms, the readings of the mentioned parameters 
( $\left.T_{W A L L}, T_{R E F}, T_{I N}, T_{O U T}, \varepsilon_{W A L L}\right)$ were transferred to a spreadsheet, where the numerical model was computed to determine the thermal transmittance according to Tejedor et al. [20].

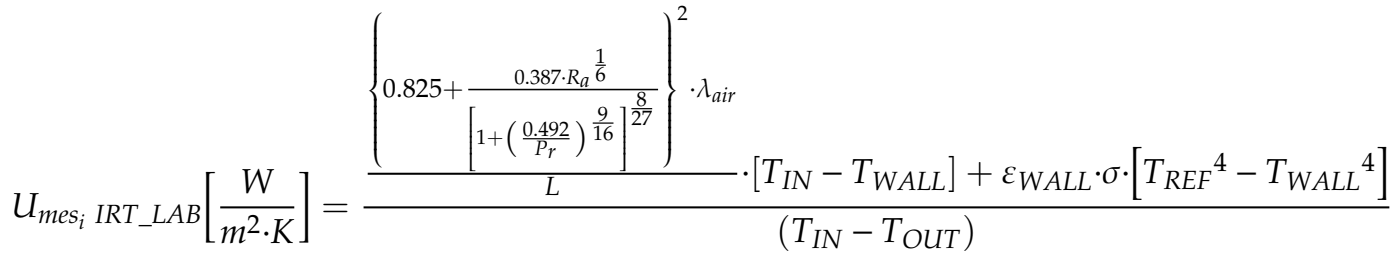

$$
\begin{aligned}
& U_{\text {mes_avg IRT_LAB }}\left[\frac{W}{m^{2} \cdot K}\right]=\frac{\sum_{i=1}^{n}\left(q_{r i}+q_{c i}\right)}{\sum_{i=1}^{n}\left(T_{I N i}-T_{\text {OUT } i}\right)}=\frac{\sum_{i=1}^{n} U_{m e s i}}{n}
\end{aligned}
$$

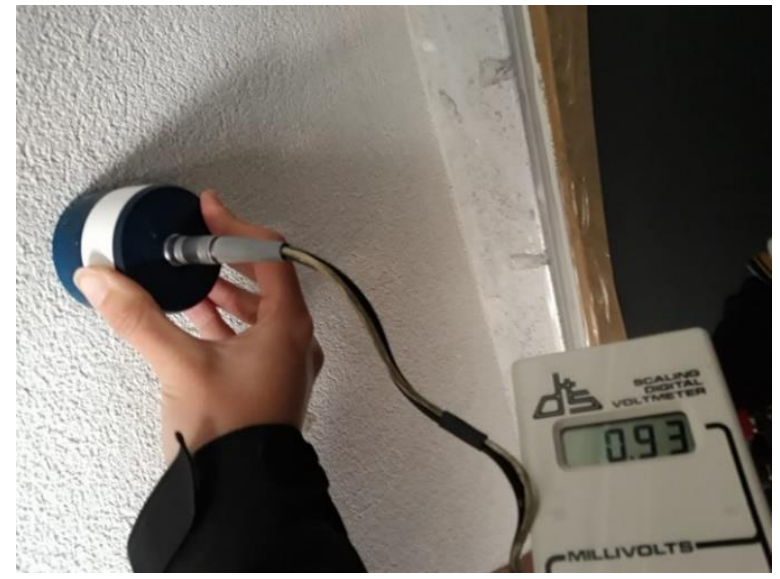

Figure 2. Use of the emissometer to determine the wall surface emissivity (0.93).

Subsequently, to validate the QIRT results, the HFM method was implemented using two transducers (TPD TND-TH) installed inside the climatic chamber and two temperature sensors (HOBO UX100) to collect indoor and outdoor hygrothermal conditions. It should be noted that the position of all sensors was set at $1.5 \mathrm{~m}$ above the floor and the distance of the IR camera to the target was $1 \mathrm{~m}$, to avoid any possible unknown heterogeneities due to air movement. The HFM tests took $72 \mathrm{~h}$ with a sampling frequency of $10 \mathrm{~min}$. In this case, the average method of ISO 9869-1:2014 [8] was followed for the data post-processing, dividing the mean density of the heat flux rate by the mean temperature difference between inside and outside the climatic chamber (Equation (4)). Previously, the instantaneous readings of the heat flux density $\left(q_{H F M} \_A B\right)$ were estimated through an Excel spreadsheet, as a product of the measured voltage signal from the sensor ( $X$ in $\mathrm{mV}$ ) and the numerical constant of the sensor provided by the manufacturer $\left(C_{H F M}\right.$ in $\left.\mathrm{W} / \mathrm{m}^{2} \cdot \mathrm{mV}\right)$, as shown in Equation (3).

$$
\begin{gathered}
q_{i H F M \_L A B}\left[W / m^{2}\right]=X \cdot C_{H F M} \\
U_{\text {mes_avg HFM } \_L A B}\left[\frac{W}{m^{2} \cdot K}\right]=\frac{\sum_{i=1}^{n} q_{i H F M} L A B}{\sum_{i=1}^{n}\left(T_{I N i}-T_{O U T i}\right)}
\end{gathered}
$$

\subsection{In Situ Testing under Dynamic Conditions}

The experimental campaign took place in an eastern wall of a detached house in Poland during Winter (from 11th January to 21st January), as seen in Figure 3. In the mentioned country, the solar irradiance in January is very low. In fact, the angle of incidence of direct solar radiation upon the wall was estimated to be lower than 60 degrees only for $2 \mathrm{~h}$ a day in Winter. During the measurements, the room was completely excluded from normal use and windows were constantly covered with the dark cotton curtains. The whole building was heated by a central water system powered by 
a gas boiler. Nevertheless, noticeable fluctuations of the heat flux were detected in the wall surface. For this reason, the conventional system was replaced by an electric heater. Regarding the case study, the wall consisted of $0.005 \mathrm{~m}$ of an adhesive reinforced with glass mesh and a thin layer of external plaster, $0.13 \mathrm{~m}$ of expanded polystyrene, $0.25 \mathrm{~m}$ of the silica brickwork, and $0.02 \mathrm{~m}$ of internal lime plaster. The stratigraphy and thermo-physical properties (from outside to inside) are shown in Table 3. According to the construction project document, the notional thermal transmittance value was estimated at $0.244 \mathrm{~W} /\left(\mathrm{m}^{2} \cdot \mathrm{K}\right)$.
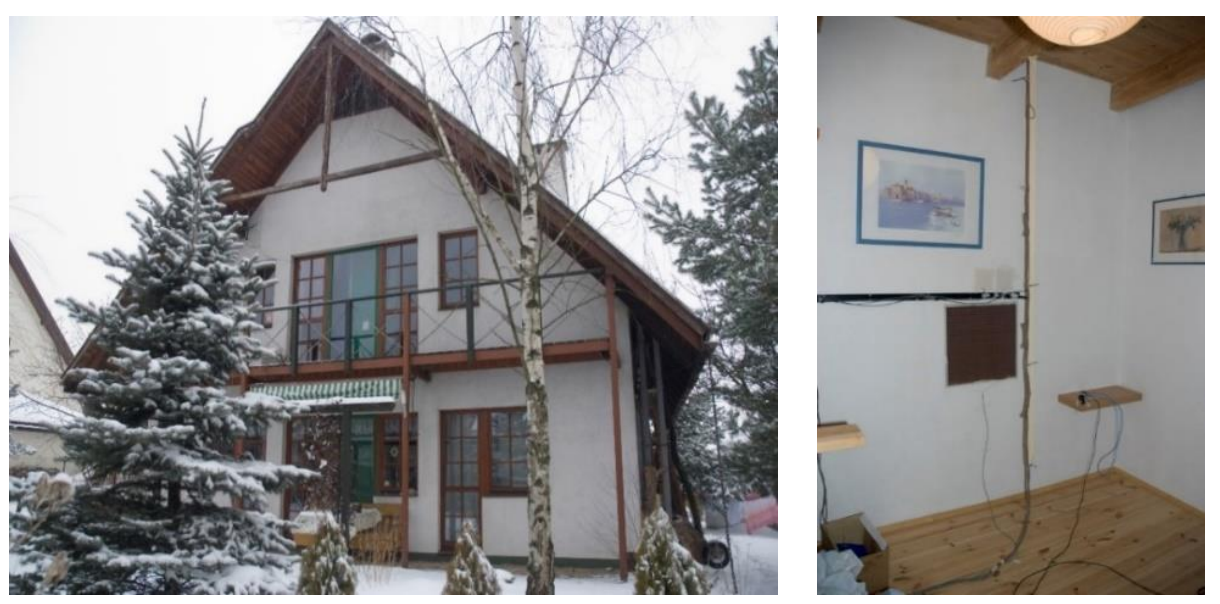

Figure 3. Detached house in Poland (left image) and distribution of the measuring equipment during the experimental campaign (right image).

Table 3. Thermo-physical properties of the eastern wall of a detached house in Poland.

\begin{tabular}{|c|c|c|c|c|c|c|c|}
\hline & $\mathbf{N} \#$ & $\begin{array}{c}\text { Material } \\
\text { Layer }\end{array}$ & $\begin{array}{l}\Delta \mathrm{x}_{\mathrm{i}} \\
(\mathrm{m})\end{array}$ & $\begin{array}{c}\lambda_{\mathrm{i}} \\
(\mathrm{W} /(\mathrm{m} \cdot \mathrm{K}))\end{array}$ & $\underset{\left(\left(\mathrm{m}^{2} \cdot \mathrm{K}\right) / \mathrm{W}\right)}{\mathrm{R}_{\mathrm{ti}}}$ & $\begin{array}{c}\mathrm{L} \\
(\mathrm{m})\end{array}$ & $\begin{array}{c}\mathrm{U}_{\mathrm{t}} \\
\left(\mathrm{W} /\left(\mathrm{m}^{2} \cdot \mathrm{K}\right)\right)\end{array}$ \\
\hline \multirow{4}{*}{$\begin{array}{l}\text { Detached House } \\
\text { (Poland) }\end{array}$} & 1 & Adhesive + external plaster & 0.005 & 0.800 & 0.006 & \multirow{4}{*}{2.5} & \multirow{4}{*}{0.244} \\
\hline & 2 & Expanded polystyrene & 0.130 & 0.037 & 3.513 & & \\
\hline & 3 & Silica brickwork (hollow block) & 0.250 & 0.750 & 0.333 & & \\
\hline & 4 & Internal lime plaster & 0.020 & 0.800 & 0.025 & & \\
\hline
\end{tabular}

UNE EN ISO 10456:2012 [40] and UNE EN ISO 6946:2012 [14] were used to calculate Ut.

The thermographic process consisted of recording automatically the inner and outer ambient air temperatures with T-type thermocouples and the wall surface temperature by means of an IR camera (ThermaCam S60) and its respective software (FLIR TOOLS+ [42]). To minimize signal noise, wall temperature was calculated as an average value of the selected measuring areas (Figure 4). In addition, it was assumed that the impact of reflected radiation could be eliminated for objects with similar emissivity when temperature difference was given. Notably, the conditions of the room fulfilled the requirements of the standard UNE EN ISO 6946:2012 [14] regarding surface heat transfer. The surfaces of the partitions had high emissivity $\left(\varepsilon_{W A L L}=0.9\right)$, and the speed of air movement did not exceed $0.1 \mathrm{~m} / \mathrm{s}$. According to the standard, the total value of the heat transfer coefficient on the wall surface can be $h_{I N}$ $=7.7 \mathrm{~W} /\left(\mathrm{m}^{2} \cdot \mathrm{K}\right)$. The basis for calculating the heat flux density was the difference between the wall surface temperature and inner air temperature, at a known value of surface heat transfer coefficient. This approach significantly simplified the procedure and reduced the number of measured parameters, as previously adopted by Kisilewicz et al. [18] and Asdrubali et al. [27]. Taking into account the information reported above and Kisilewicz's approach [18], the instantaneous heat flux density and the average measured U-value can be obtained by Equations (5) and (6).

$$
\begin{gathered}
q_{i I R T \_D H}\left[\mathrm{~W} / \mathrm{m}^{2}\right]=h_{I N} \cdot\left(T_{I N}-T_{W A L L}\right) \\
U_{\text {mes_avg } I R T \_D H}\left[\frac{W}{m^{2} \cdot K}\right]=\frac{\sum_{i=1}^{n} q_{I R T i \_D H}}{\sum_{i=1}^{n}\left(T_{I N i}-T_{\text {OUTi }}\right)}
\end{gathered}
$$




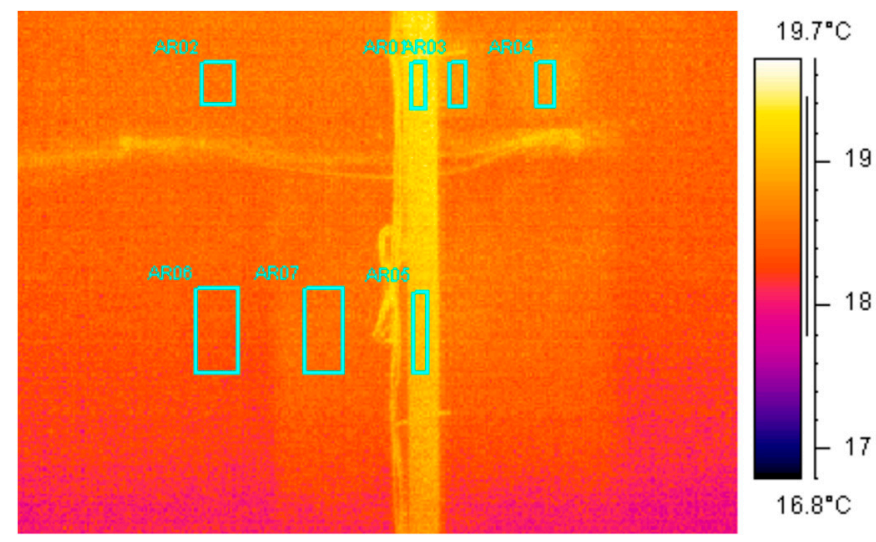

Figure 4. Infrared photo of the measuring field, vertical strip in the photo center is paper tape in front of the wall, in the background a vague contour of a big-size heat flux meter.

During the IRT test, a HFM transducer (Ahlborn W150-2) was also used to assess the U-value. It was installed on the central part of the wall (Figure 3, right image). The location of the heat flux transducer was confirmed by a qualitative infrared inspection in order to avoid local thermal bridges or edges. In this procedure, inner and outer air temperature, and wall surface temperatures, were collected using T-type thermocouples connected with a data logger. The mentioned heat flux sensor was characterized to have the dimensions of $0.5 \mathrm{~m} \times 0.5 \mathrm{~m}$ and an accuracy of $\pm 5 \%$, while the thermocouples had a precision of $\pm 0.3^{\circ} \mathrm{C}$. In addition, air velocity at internal surface of the tested wall was randomly checked by a thermo-anemometer (FVA605 TA10). Data measured by the HFM sensor were recorded with a time step of $30 \mathrm{~min}$, synchronized with the QIRT measurement. Concerning the data post-processing of the HFM method, the ISO 9869-1:2014 [8] was implemented. Heat flux density $\left(q_{H F M}\right)$ was calculated in an Excel spreadsheet, multiplying the measured voltage signal from the sensor $(X$ in $\mathrm{mV})$ and the numerical constant $\left(C_{H F M}\right.$ in $\left.\mathrm{W} / \mathrm{m}^{2} \cdot \mathrm{mV}\right)$ provided by the manufacturer of the sensor, as seen in Equation (7). In the same way than IRT method, the average measured U-values were determined by the total specific heat flux and the thermal gradient between inside and outside the building (Equation (8)).

$$
\begin{gathered}
q_{i H F M \_D H}\left[W / m^{2}\right]=X \cdot C_{H F M} \\
U_{\text {mes_avg } H F M \_D H}\left[\frac{W}{m^{2} \cdot K}\right]=\frac{\sum_{i=1}^{n} q_{i H F M \_D H}}{\sum_{i=1}^{n}\left(T_{I N i}-T_{\text {OUTi }}\right)}
\end{gathered}
$$

\section{Results}

\subsection{Laboratory Testing under Steady-State Conditions}

A total of three quantitative IRT tests of the experimental mock-up were conducted to guarantee a good reliability of the results, maintaining the same boundary conditions during the entire measurement campaign. The unique difference was the selection of the wall area. As mentioned above, the practitioner had to post-process the 120 thermograms of each test with a specific software and transfer the measurements ( $T_{W A L L}, T_{R E F}$, and $\varepsilon_{W A L L}$ ) to a spreadsheet where the algorithm was computed according to Tejedor et al. [20]. Subsequently, and to validate the outcomes, the HFM method was also implemented.

During the experimental campaigns, the environmental conditions $\left(T_{I N}\right.$ and $\left.T_{\text {OUT }}\right)$ and the parameters that correspond to the thermal performance of the specimen $\left(T_{W A L L}\right.$ and $\left.T_{R E F}\right)$ remained practically constant (Figure 5). It should be pointed out that $T_{\text {WALL }}$ and $T_{\text {REF }}$ described soft regular cycles every $20 \mathrm{~min}$. This could be given by the activation of the fans of the climatic chamber when $T_{I N}$ was under the set point temperature. Covering completely the internal surfaces of the climatic chamber with a black cardboard allowed to avoid uncontrolled reflection indexes and smoothed the 
effect of the heating unit that could have led to different air speed values along the wall surface. Hence, the stationary regime can be adopted for the application of the algorithm to compute the thermal transmittance of highly insulated walls by QIRT. Indeed, the difference between the maximum and minimum values turned out to be less than $0.5^{\circ} \mathrm{C}$.

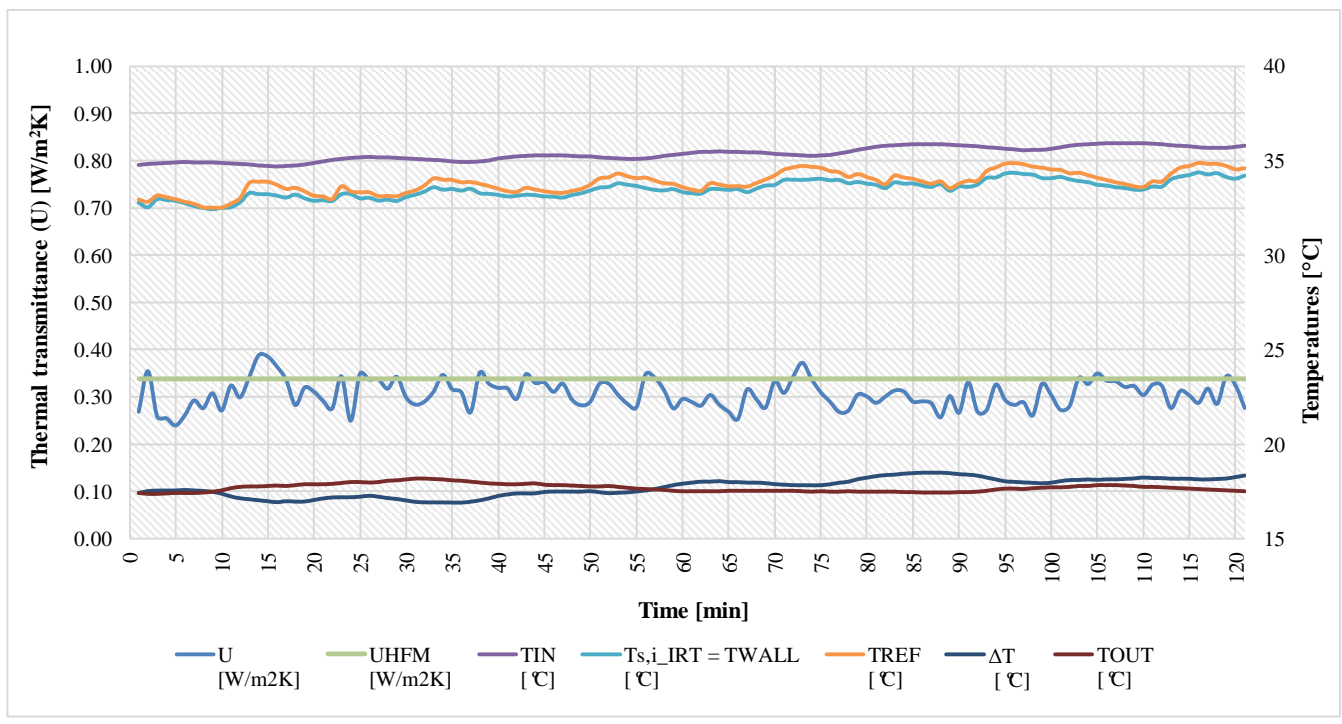

Figure 5. Evolution of the measured U-value and environmental conditions of the heavy-multi wall tested in the climatic chamber under steady-state conditions.

The results of both non-invasive techniques are shown in Table 4 . The thermal transmittance values oscillated from 0.316 to $0.334 \mathrm{~W} / \mathrm{m}^{2} \cdot \mathrm{K}$ using QIRT, while the HFM measurements were from 0.292 to $0.338 \mathrm{~W} / \mathrm{m}^{2} \cdot \mathrm{K}$. Hence, it can be extrapolated that the thermal behavior of the specimen was slightly similar in different wall areas and all QIRT measurements were in line with the HFM readings. In fact, the relative deviation between techniques was estimated at $2.9 \%$. However, the thermographic values tended to be a bit overestimated respect to the HFM readings (Table 4, Figure 5). Concerning the comparative analysis with the nominal design data, both non-invasive methods presented a good adjustment to the theoretical U-value, following UNE EN ISO 10456:2012 [41] and UNE EN ISO 6946:2012 [14]. The measured thermal transmittances differed from the theoretical value in $3.19 \%$ for the QIRT and $0.32 \%$ for the HFM.

Table 4. Comparative analysis between the theoretical and the measured thermal transmittance of the experimental mock-up using Quantitative IRT (QIRT) and Heat Flux Method (HFM).

\begin{tabular}{|c|c|c|c|c|c|c|c|c|}
\hline & $\begin{array}{c}\mathrm{U}_{\mathrm{QIRT}} \\
\left(\mathrm{W} / \mathrm{m}^{2} \cdot \mathrm{K}\right)\end{array}$ & $\underset{\left(\mathrm{W} / \mathrm{m}^{2} \cdot \mathrm{K}\right)}{\mathrm{U}_{\mathrm{HFM}}}$ & $\begin{array}{c}U_{t} \\
\left(W / \mathrm{m}^{2} \cdot K\right)\end{array}$ & $\begin{array}{l}\text { U }_{\text {QIRT avg }} \\
\left(\mathrm{W} / \mathbf{m}^{2} \cdot \mathrm{K}\right)\end{array}$ & $\begin{array}{l}\text { U UFM avg } \\
\left(\mathrm{W} / \mathrm{m}^{2} \cdot \mathrm{K}\right)\end{array}$ & $\underset{(\%)}{\Delta U_{\text {IRT }-\mathrm{t}} / \mathrm{U}_{\mathrm{t}}}$ & $\underset{(\%)}{\Delta U_{(\% M-t} / U_{t}}$ & $\underset{(\%)}{\Delta \mathrm{U}_{\mathrm{NDT}} / \mathrm{U}_{\mathrm{HFM}}}$ \\
\hline TEST 1 & 0.320 & 0.338 & \multirow{3}{*}{0.313} & \multirow{3}{*}{0.323} & \multirow{3}{*}{0.314} & \multirow{3}{*}{3.19} & \multirow{3}{*}{0.32} & \multirow{3}{*}{2.90} \\
\hline TEST 2 & 0.316 & 0.313 & & & & & & \\
\hline TEST 3 & 0.334 & 0.292 & & & & & & \\
\hline
\end{tabular}

\subsection{In Situ Testing under Dynamic Conditions}

Having conducted the HFM and IRT measurements, the main outcomes are shown in Figures 6-9. Ambient air temperatures and the heat flux values, calculated using the infrared measurements, are presented in Figure 6. For the first five days of measurements, the sky was covered with clouds. In this case, the fluctuations of outdoor and indoor air temperatures did not exceed $3{ }^{\circ} \mathrm{C}$ and $0.5^{\circ} \mathrm{C}$, respectively. Therefore, it was an optimum period for computing the thermal insulation of the wall in natural conditions. 


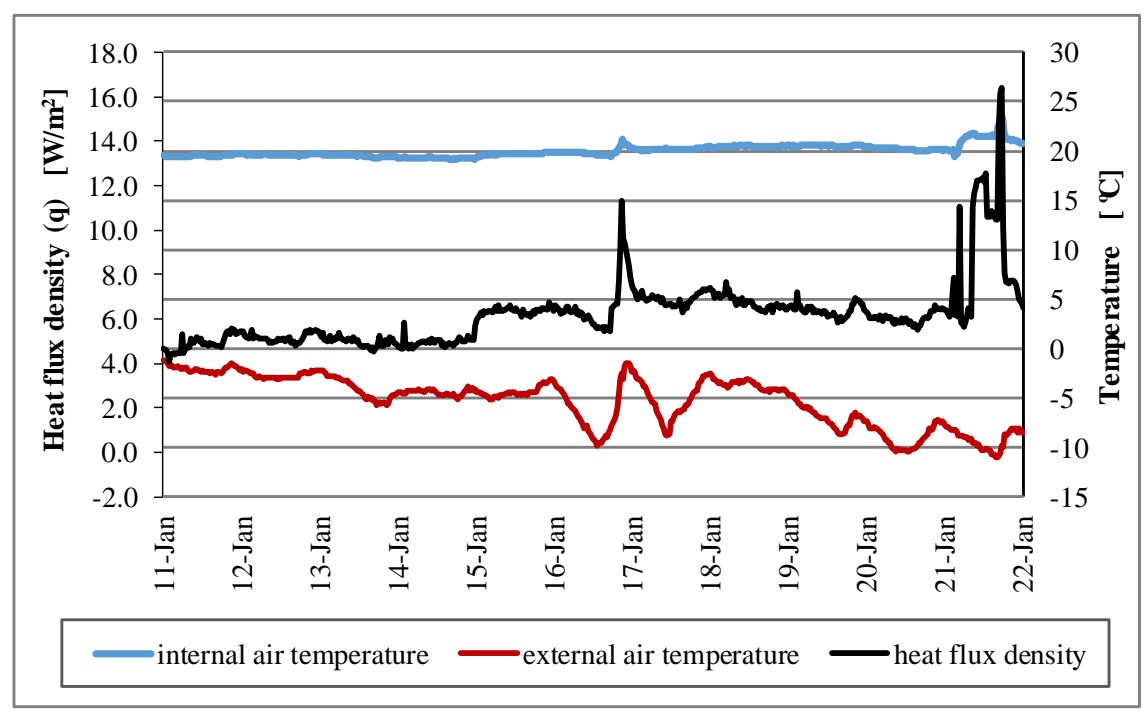

Figure 6. Environmental temperature and calculated heat flux density.

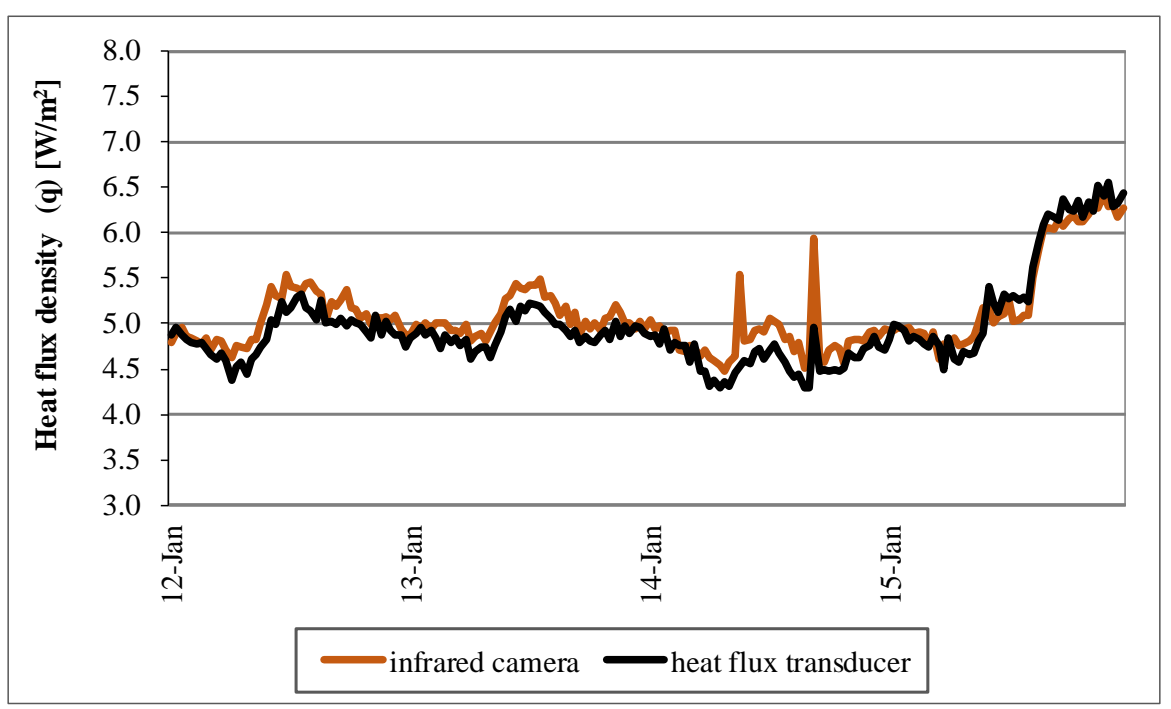

Figure 7. Measured heat flux using a heat transducer and infrared camera.

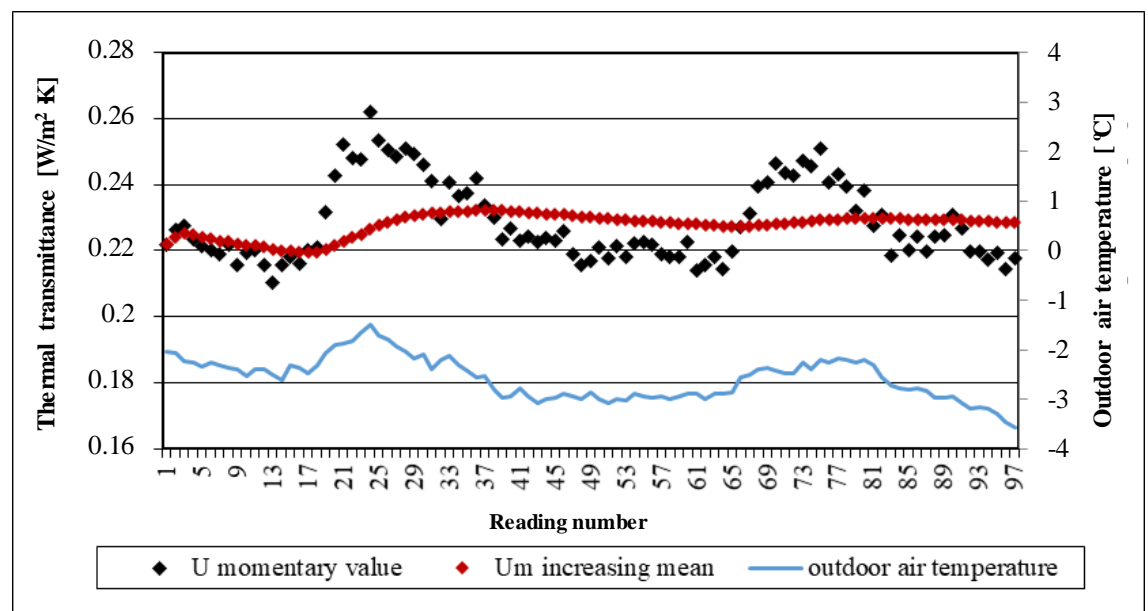

Figure 8. Thermal transmittance versus outdoor air temperature. 


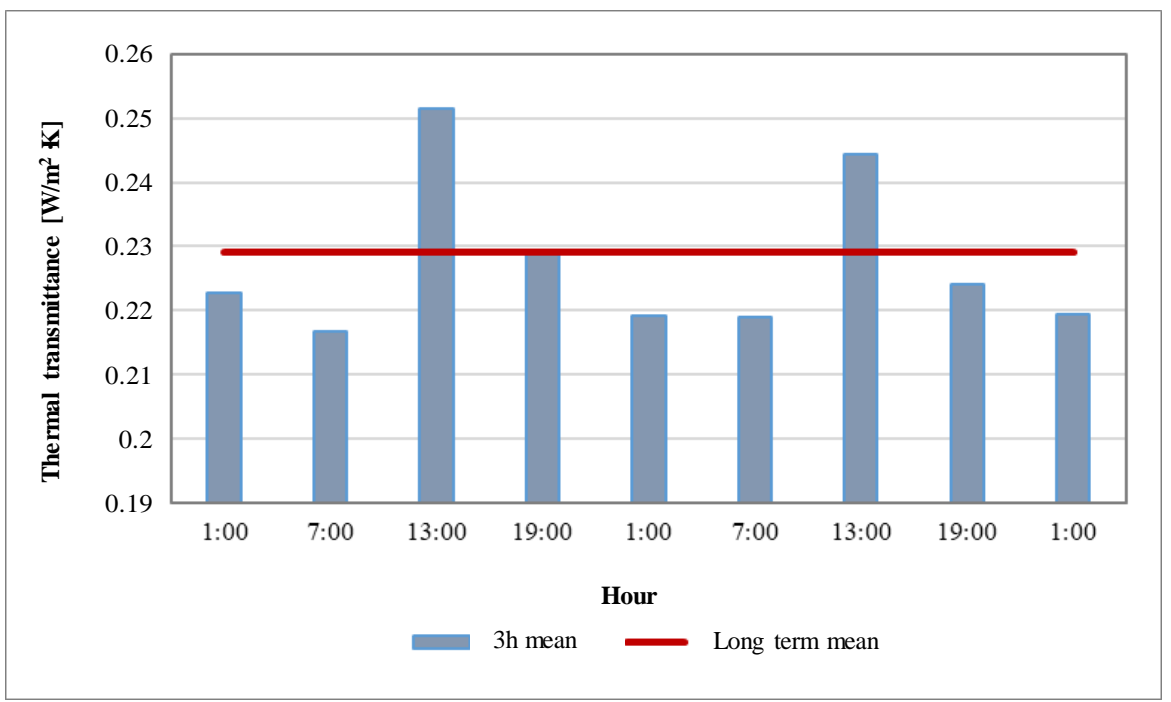

Figure 9. Mean thermal transmittance for $3 \mathrm{~h}$-periods and at long term.

The clear sky on 17th January caused a stronger fluctuation (up and down) in the outside temperature. Despite the covered windows, transmitted solar radiation resulted in a small increase of $\mathrm{T}_{\mathrm{IN}}$ and a greater heat flux value through the transducer. In the following days, the weather was cloudy again with very limited diurnal changes in the outside temperature. Another peak in heat flux appeared on the sunny days of 21st and 22nd January.

Figure 7 shows the heat flux values calculated using both NDT methods. Only a period with heavy cloud cover (from 12nd January to 15th January) was accepted for further analysis. External temperature insignificantly decreased $0.5^{\circ} \mathrm{C}$ within this period and consequently, internal energy exchange of the external wall was not relevant in these conditions and dynamic structural coefficients were not applied. Despite of a slight pulsation of the external temperature and practically constant internal temperature, the heat flux through the façade described regular cyclical changes.

The results of the statistical analysis between the instantaneous measured heat fluxes by HFM and quantitative IRT are shown in Table 5. In terms of variability, the discrepancy between the average heat flux values obtained from both NDT methods was equal to $1.47 \%$. Even, it was smaller than the transducer accuracy declared by the manufacturer. As regards the CV, defined as a ratio of SD of the measurements to the average flux density, it was found to be $3.5 \%$ for the HFM and QIRT. Hence, the dispersion of the instantaneous measurements was very low. The conducted measurements confirmed that the thermal imaging camera with appropriate technical parameters allows the measurement of the wall heat flux with the required accuracy under dynamic conditions.

Table 5. Comparative analysis between the heat fluxes of the detached house' façade using Quantitative IRT (QIRT) and Heat Flux Method (HFM).

\begin{tabular}{cccccc}
\hline Type of Test & $\begin{array}{c}\text { Mean } \\
\text { Heat Flux } \\
\left(\mathbf{W} / \mathbf{m}^{2}\right)\end{array}$ & $\begin{array}{c}\text { Standard } \\
\text { Deviation } \\
\left(\mathbf{W} / \mathbf{m}^{2}\right)\end{array}$ & $\begin{array}{c}\text { Difference } \\
\text { of Mean Values } \\
\left(\mathbf{W} / \mathbf{m}^{2}\right)\end{array}$ & $\begin{array}{c}\text { Standard Deviation } \\
\text { of the Differences } \\
\left(\mathbf{W} / \mathbf{m}^{2}\right)\end{array}$ & $\begin{array}{c}\text { Variability } \\
\text { of the Differences of } \\
\text { the Mean Heat Flux Value } \\
(\%)\end{array}$ \\
\hline Heat transducer & 5.247 & 0.684 & 0.077 & 0.184 \\
\hline Infrared camera & 5.324 & 0.577 & 0.5 \\
\hline
\end{tabular}

The completed long measurement period allowed the rational selection of a most favorable calculation period. Therefore, from the whole measurement period shown in Figure 6, the two-day cloudy period starting on 12th January at 00.15 was chosen to calculate the measured thermal transmittance according to Kisilewicz's approach [18]. In order to reduce the potential effect of unknown conditions before the start of the measurements, the beginning of the calculation period 
was taken almost one day later. Figure 8 plots the instantaneous U-values and the increasing mean values of the U-value, calculated through IRT measurements for the mentioned period starting on 12th January at 00:15. The pulsating nature of the flux and the associated fluctuations of the $\mathrm{U}$ value are clearly visible here. Outdoor air temperature during this period ranged from $-1.5^{\circ} \mathrm{C}$ to $-3.6{ }^{\circ} \mathrm{C}$, while instantaneous $\mathrm{U}$ values oscillated from $0.262 \mathrm{~W} /\left(\mathrm{m}^{2} \cdot \mathrm{K}\right)$ to $0.211 \mathrm{~W} /\left(\mathrm{m}^{2} \cdot \mathrm{K}\right)$ with the mean value for the whole period equal to $0.229 \mathrm{~W} /\left(\mathrm{m}^{2} \cdot \mathrm{K}\right)$. The maximum instantaneous deviation from mean value was equal to $14 \%$ while a ratio of the $\mathrm{SD}$ to the mean value was $5 \%$. After the first day of the considered period, the measured U-value was very close to $0.229 \mathrm{~W} /\left(\mathrm{m}^{2} \cdot \mathrm{K}\right)$ and its variability was very small. The standard deviation of the instantaneous $\mathrm{U}$-value was $0.012 \mathrm{~W} /\left(\mathrm{m}^{2} \cdot \mathrm{K}\right)$ while deviation of the mean increasing transmittance $U_{m}$ was 6 times lower and equal to $0.002 \mathrm{~W} /\left(\mathrm{m}^{2} \cdot \mathrm{K}\right)$. It can be concluded that even if the results of a long-lasting measurement and the most favorable time period are selected, the random instantaneous values may still significantly differ from the actual thermal transmittance of the component.

The average U-value obtained from the HFM transducer measurements was equal to $0.221 \mathrm{~W} /\left(\mathrm{m}^{2} \cdot \mathrm{K}\right)$. The deviation between HFM and quantitative IRT was found to be $3.61 \%$. However, relative deviation between the theoretical and the average measured U-value was estimated at $6.15 \%$ for QIRT and $9.43 \%$ for HFM, as seen in Table 6. Hence, the findings revealed that quantitative infrared thermography could be more accurate than HFM. Asdrubali et al. [43] dealt with the causal factors of the discrepancies generated between measurements and nominal values, highlighting, material data overstated by manufacturers, discontinuities of the insulating layer, influence of wind and rain, etc.

Table 6. Comparative analysis between the theoretical and the measured thermal transmittance of the detached house' façade using Quantitative IRT (QIRT) and Heat Flux Method (HFM).

\begin{tabular}{|c|c|c|c|c|c|c|}
\hline Type of Test & $\begin{array}{c}U_{t} \\
\left(W / m^{2} \cdot K\right)\end{array}$ & $\begin{array}{l}\text { U } \begin{array}{l}\text { QIRT avg } \\
\left(\mathrm{W} / \mathrm{m}^{2} \cdot \mathrm{K}\right)\end{array}\end{array}$ & $\begin{array}{l}\mathrm{U}_{\mathrm{HFM} \text { avg }} \\
\left(\mathrm{W} / \mathrm{m}^{2} \cdot \mathrm{K}\right)\end{array}$ & $\underset{(\%)}{\Delta U_{\text {IRT - } t / U_{t}}}$ & $\underset{(\%)}{\Delta U_{\text {HFM }-\mathrm{t}} / \mathrm{U}_{\mathrm{t}}}$ & $\underset{(\%)}{\Delta \mathrm{U}_{\mathrm{NDT}} / \mathrm{U}_{\mathrm{HFM}}}$ \\
\hline Long-lasting test & 0.244 & 0.229 & 0.221 & 6.15 & 9.43 & 3.61 \\
\hline
\end{tabular}

Figure 9 presents the outcomes of testing the wall under transient regime, based on the mean value of 3-h periods. Regarding the nine periods that were considered in this analysis, the following aspects could be extrapolated: (i) the two periods that corresponded to the mid-day differed more than $10 \%$; (ii) the six periods which corresponded to the night hours differed less than $5 \%$. Therefore, the selection of a specific calculation period could be very difficult to define, but also important for the precision of the measurement.

\section{Discussions and Conclusions}

The most important contribution of this research was the analysis of the impact of stationary and dynamic conditions (attributed to the climate variability of different European countries) in the determination of the measured U-value of heavy multi-leaf walls using quantitative infrared thermography and heat flux meter.

In southern European countries, the literature review suggested some recommendations to conduct measurements in existing buildings by NDT methods: (i) tests should be conducted on early morning or after the sunset in order to achieve steady-state conditions [20-22]; (ii) a correct estimation of the heat transfer coefficients and parameters related to the calibration of the IR camera should be required [1]; (iii) IRT survey should be performed when stable weather conditions can be guaranteed in-prior [1]; (iv) the metering section of the HFM should be defined by a qualitative inspection prior to the experimental campaign [44]; (v) the temperature gradient across the building envelope should range from 7 to $10^{\circ}$ [32]; (vi) the type of heating unit can influence the results, since non-homogeneous heat fluxes and fluctuations of wall temperatures could be attributed to air peak currents [20]. However, some of the mentioned requirements can be a challenging task in Northern European countries where the climatic conditions are often more extreme and more variable. 
As a consequence, a more demanding procedure of testing should be performed. For this reason, two case studies were chosen. The first one consisted of a typical construction of Portugal reproduced in a climatic chamber and tested under steady-state conditions, while the second one was a building façade of a detached house in Poland and evaluated under dynamic conditions.

In terms of execution, the results of the laboratory indicated that the boundary conditions reported in the literature review could be partially adopted to analyze a well-insulated wall in a southern European country. Nevertheless, additional recommendations should be taken into account if the test is performed inside a climatic chamber. Firstly, the inner side of the climatic chamber should be covered, to avoid the influence of unknown reflection indexes as well as the different air speeds caused by the heating unit. Secondly, the specimen should be pre-conditioned at least $72 \mathrm{~h}$, to guarantee stable conditions during the experimental campaign. Thirdly, a thermal gradient around of $15^{\circ}$ could lead to a better adjustment with HFM measurements in the case of highly insulated walls. Concerning the detached house, the analysis revealed that the worst discrepancy between HFM and IRT was given at 1 p.m. Specifically, the average U-value from IRT was $0.262 \mathrm{~W} / \mathrm{m}^{2} \cdot \mathrm{K}$ and the value of HFM was estimated to be $0.221 \mathrm{~W} / \mathrm{m}^{2} \cdot \mathrm{K}$. Only the measurements at $1 \mathrm{a} . \mathrm{m}$. or up to $7 \mathrm{p} . \mathrm{m}$. were within the range of the HFM and the long term mean by IRT $\left(0.221 \mathrm{~W} / \mathrm{m}^{2} \cdot \mathrm{K}\right.$ and $0.229 \mathrm{~W} / \mathrm{m}^{2} \cdot \mathrm{K}$ respectively) for northern European countries. The preferred measuring period corresponded to heavy cloud cover and moderate wind speed. This ensures both reduction of external temperature fluctuations and solar radiation disturbances outside and inside the building. Periods of overcast sky are usually not predictable or cyclical, only a long measurement duration (at least 7-10 days) allows later (ex post) selection of the appropriate shorter period for calculations that would guarantee high measurement accuracy. Thanks to specially selected weather conditions of in-situ measurement, and then the subsequent selection of the period adopted for the calculations, it is possible to avoid errors related to energy accumulation in building envelopes. Analytical dynamic calculations under highly variable conditions are more difficult and require a lot of detailed material information, but such data is usually not available when testing existing facilities. As regards the indoor environment, the findings of the detached house also demonstrated that the heat transfer conditions must be individually determined on the basis of measuring the speed of air movement near the tested partition when air heating is used. During such measurements, attention should be paid to the strongly turbulent nature of the air flow near the wall at higher speeds and to the disturbances caused by the measurement itself.

In terms of precision of the method, the deviation between in situ IRT tests and HFM measurements was $3.6 \%$ for the façade investigated in Poland under transient regime, applying the quantitative IRT method proposed by Kisilewicz [18]. Slightly better accuracy $(2.9 \%)$ was achieved in the laboratory of Portugal under stationary conditions, using the quantitative IRT method reported in Tejedor et al. [20]. Therefore, climatic conditions could imply to implement different approaches to achieve similar precision levels in heavy-multi leaf walls with low U-value. It should be noted that the comparative analysis between the nominal design data and the experimental data also revealed that non-invasive techniques could be less accurate for this type of walls in northern European countries, obtaining a deviation around of $9 \%$ for the HFM. Taking into account that this study is a proof of concept, future steps of research should involve more case studies in different climate regions.

Author Contributions: Conceptualization, T.K. and B.T.; methodology, T.K. and B.T.; software, T.K. and B.T.; validation, T.K. and B.T.; formal analysis, T.K. and B.T.; investigation, T.K. and B.T.; resources, V.P.d.F. and T.K.; data curation, E.B.; writing-original draft preparation, T.K. and B.T.; writing-review and editing, E.B., K.N.-D., and U.B.; visualization, E.B., U.B., and K.N.-D.; supervision, V.P.d.F.; project administration, V.P.d.F.; funding acquisition, V.P.d.F. and T.K. All authors have read and agreed to the published version of the manuscript.

Funding: This work was financially supported by UIDB/04708/2020 of the CONSTRUCT-Instituto de I\&D em Estruturas e Construções-and national funds through the FCT/MCTES (PIDDAC). This work was also financed by the Polish National Agency for Academic Exchange (NAWA) under the International Academic Partnership Program within the framework of the grant: E-mobility and sustainable materials and technologies EMMAT(PPI/APM/2018/1/00027). 
Conflicts of Interest: The authors declare no conflict of interest. The funders had no role in the design of the study; in the collection, analyses, or interpretation of data; in the writing of the manuscript, or in the decision to publish the results.

\section{Nomenclature}

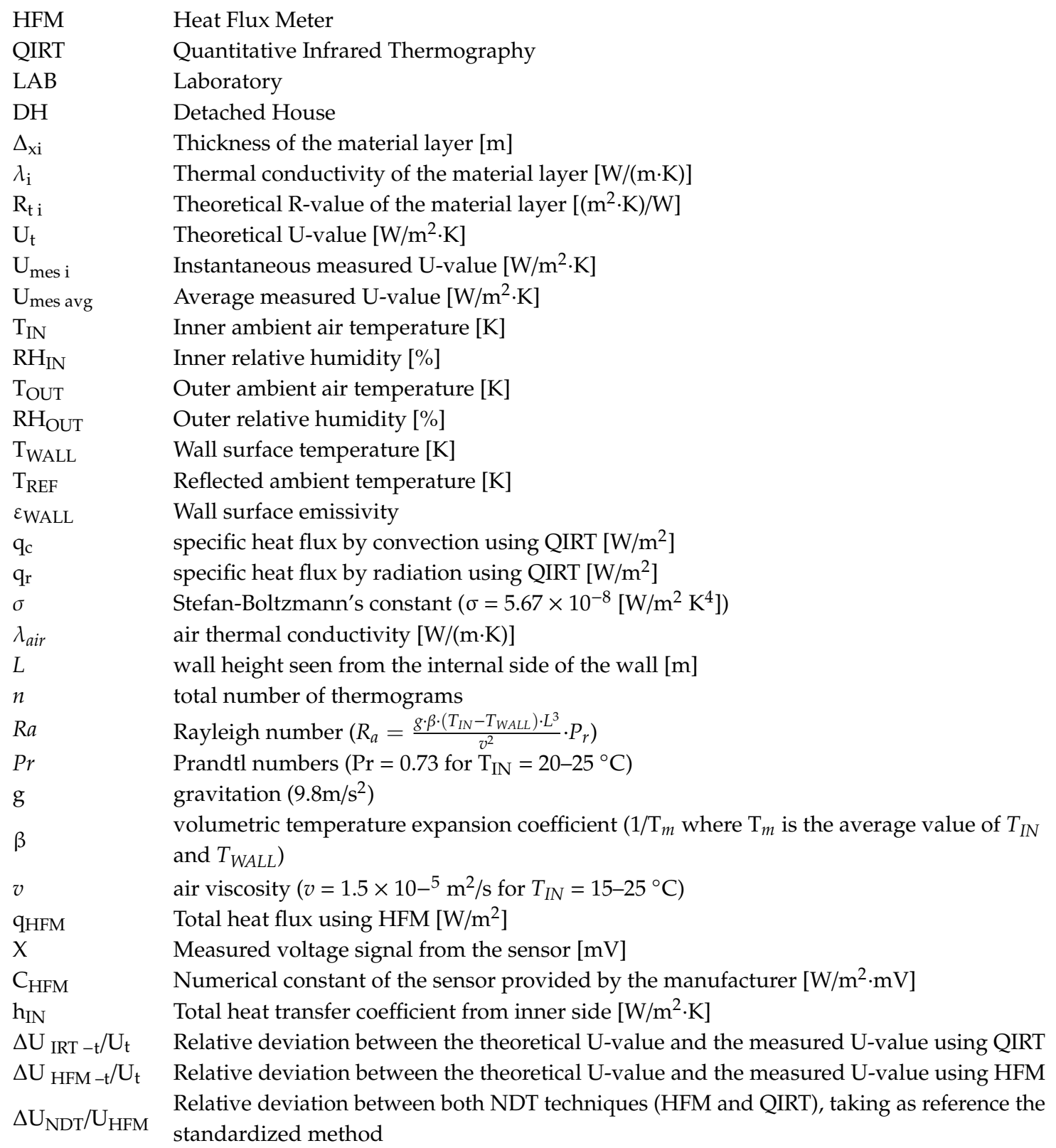

\section{References}

1. Nardi, I.; Lucchi, E.; De Rubeis, T.; Ambrosini, D. Quantification of heat energy losses through the building envelope: A state-of-the-art with critical and comprehensive review on infrared thermography. Build. Environ. 2018, 146, 190-205. [CrossRef]

2. Evola, G.; Marletta, L.; Costanzo, V.; Caruso, G. Different strategies for improving summer thermal comfort in heavyweight traditional buildings. Energy Procedia 2015, 78, 3228-3233. [CrossRef] 
3. Lucchi, E. Applications of the infrared thermography in the energy audit of buildings: A review. Renew. Sustain. Energy Rev. 2018, 82, 3077-3090. [CrossRef]

4. American Society for Testing Materials. ASTM C1060-90. Standard Practice for Thermographic Inspection of Insulation Installations in Envelope Cavities of Frame Buildings; American Society for Testing Materials: West Conshohocken, PA, USA, 2003.

5. International Organization for Standardization. ISO 6781-3:2015. Performance of Buildings. Detection of Heat, Air and Moisture Irregularities in Buildings by Infrared Methods_Part 3: Qualifications of Equipment Operators, Data Analysts and Report Writers; International Organization for Standardization: Geneva, Switzerland, 2015.

6. International Organization for Standardization. UNE EN 13187:1998. Thermal Performance of Buildings. Qualitative Detection of Thermal Irregularities in Building Envelopes. Infrared Method; International Organization for Standardization: Geneva, Switzerland, 1998.

7. International Organization for Standardization. ISO 9869-2: 2018 Thermal Insulation-Building Elements-In-Situ Measurements of Thermal Resistance and Thermal Transmittance. Part 2: Infrared Method for Frame Structures Dwelling; International Organization for Standardization: Geneva, Switzerland, 2018.

8. International Organization for Standardization. ISO 9869-1:2014 Thermal Insulation. Building Elements. In-Situ Measurement of Thermal Resistance and Thermal Transmittance. Part 1: Heat Flow Meter Method; International Organization for Standardization: Geneva, Switzerland, 2014.

9. Gaspar, K.; Casals, M.; Gangolells, M. A comparison of standardized calculation methods for in situ measurements of façades U-value. Energy Build. 2016, 130, 592-599. [CrossRef]

10. Kisilewicz, T. Thermal resistance of a wall determined in non-stationary boundary conditions. In Proceedings of the 1st Central European Symposium on Building Physics, Research on Building Physics, Kraków-Łódź, Poland, 13-15 September 2010; pp. 171-176, ISBN 978-83-7283-367-9.

11. International Organization for Standardization. ISO 13786: 2017. Thermal Performance of Building Components—Dynamic Thermal Characteristics —Calculation Methods; International Organization for Standardization: Geneva, Switzerland, 2017.

12. Kossecka, E. Problem of the measured R-value error estimation. Arch. Civ. Eng. 1993, 39, 413-427.

13. Evangelisti, L.; Guattari, C.; Gori, P.; Vollaro, R.D.L.; Asdrubali, F. Experimental investigation of the influence of convective and radiative heat transfers on thermal transmittance measurements. Int. Commun. Heat Mass Transf. 2016, 78, 214-223. [CrossRef]

14. International Organization for Standardization. UNE EN ISO 6946:2012 (ISO 6946:2007) Building Components and Building Elements. Thermal Resistance and Thermal Transmittance. Calculation Method; International Organization for Standardization: Geneva, Switzerland, 2012.

15. Evangelisti, L.; Guattari, C.; Asdrubali, F. Influence of heating systems on thermal transmittance evaluations: Simulations, experimental measurements and data post-processing. Energy Build. 2018, 168, 180-190. [CrossRef]

16. Atsonios, I.A.; Mandilaras, I.; Kontogeorgos, D.A.; Founti, M.A. A comparative assessment of the standardized methods for the in-situ measurement of the thermal resistance of building walls. Energy Build. 2017, 154, 198-206. [CrossRef]

17. Marino, B.M.; Muñoz, N.; Thomas, L.P. Estimation of the surface thermal resistances and heat loss by conduction using thermography. Appl. Therm. Eng. 2017, 114, 1213-1221. [CrossRef]

18. Kisilewicz, T.; Wróbel, A. Quantitative infrared wall inspection. In Proceedings of the 2010 International Conference on Quantitative InfraRed Thermography, Quebec, ON, Canada, 24-29 June 2010; pp. 589-594. [CrossRef]

19. Lucchi, E.; Roberti, F.; Alexandra, T. Definition of an experimental procedure with the hot box method for the thermal performance evaluation of inhomogeneous walls. Energy Build. 2018, 179, 99-111. [CrossRef]

20. Tejedor, B.; Casals, M.; Gangolells, M.; Roca, X. Quantitative internal infrared thermography for determining in-situ thermal behaviour of façades. Energy Build. 2017, 151, 187-197. [CrossRef]

21. Albatici, R.; Tonelli, A.M. Infrared thermovision technique for the assessment of thermal transmittance value of opaque building elements on site. Energy Build. 2010, 42, 2177-2183. [CrossRef]

22. Fokaides, P.A.; Wongwises, S. Application of infrared thermography for the determination of the overall heat transfer coefficient (U-Value) in building envelopes. Appl. Energy 2011, 88, 4358-4365. [CrossRef] 
23. Dall'O', G.; Sarto, L.; Panza, A. Infrared Screening of Residential Buildings for Energy Audit Purposes: Results of a Field Test. Energies 2013, 6, 3859-3878. [CrossRef]

24. Nardi, I.; Sfarra, S.; Ambrosini, D. Quantitative thermography for the estimation of the U-value: State of the art and a case. J. Phys. Conf. Ser. 2014, 547. [CrossRef]

25. Danielski, I.; Fröling, M. In-situ measurements of thermal properties of building fabrics using thermography under non-steady state heat flow conditions. Infrastructures 2018, 3, 20. [CrossRef]

26. Bienvenido-Huertas, D.; Moyano, J.; Marín, D.; Fresco-Contreras, R.; Marín-García, D. Review of in situ methods for assessing the thermal transmittance of walls. Renew. Sustain. Energy Rev. 2019, 102, 356-371. [CrossRef]

27. Asdrubali, F.; Baldinelli, G.; Bianchi, F. A quantitative methodology to evaluate thermal bridges in buildings. Appl. Energy 2012, 97, 365-373. [CrossRef]

28. Ficco, G.; Iannetta, F.; Ianniello, E.; Alfano, F.R.D.; Dell'Isola, M. U-value in situ measurement for energy diagnosis of existing buildings. Energy Build. 2015, 104, 108-121. [CrossRef]

29. Nardi, I.; Paoletti, D.; Ambrosini, D.; De Rubeis, T.; Sfarra, S. Validation of quantitative IR thermography for estimating the U-value by a hot box apparatus. J. Physics: Conf. Ser. 2015, 655, 012006. [CrossRef]

30. Nardi, I.; Ambrosini, D.; De Rubeis, T.; Sfarra, S.; Perilli, S.; Pasqualoni, G. A comparison between thermographic and flow-meter methods for the evaluation of thermal transmittance of different wall constructions. J. Physics: Conf. Ser. 2015, 655, 012007. [CrossRef]

31. Nardi, I.; Paoletti, D.; Ambrosini, D.; De Rubeis, T.; Sfarra, S. U-value assessment by infrared thermography: A comparison of different calculation methods in a Guarded Hot Box. Energy Build. 2016, 122, 211-221. [CrossRef]

32. Tejedor, B.; Casals, M.; Gangolells, M. Assessing the influence of operating conditions and thermophysical properties on the accuracy of in-situ measured $U$-values using quantitative internal infrared thermography. Energy Build. 2018, 171, 64-75. [CrossRef]

33. Tejedor, B.; Casals, M.; Macarulla, M.; Giretti, A. U-value time series analyses: Evaluating the feasibility of in-situ short-lasting IRT tests for heavy multi-leaf walls. Build. Environ. 2019, 159, 106123. [CrossRef]

34. Tejedor, B.; Barreira, E.; Almeida, R.M.; Casals, M. Thermographic 2D U-value map for quantifying thermal bridges in building façades. Energy Build. 2020, 224, 110176. [CrossRef]

35. International Organization for Standardization. UNE EN 1934:1998 Thermal Performance of Buildings_Determination of Thermal Resistance by Hot Box Method Using Heat Flow-Masonry; International Organization for Standardization: Geneva, Switzerland, 1998.

36. Lucchi, E. Thermal transmittance of historical stone masonries: A comparison among standard, calculated and measured data. Energy Build. 2017, 151, 393-405. [CrossRef]

37. Lehmann, B.; Wakili, K.G.; Frank, T.; Collado, B.V.; Tanner, C. Effects of individual climatic parameters on the infrared thermography of buildings. Appl. Energy 2013, 110, 29-43. [CrossRef]

38. Danielski, I.; Fröling, M. Diagnosis of Buildings' Thermal Performance-A Quantitative Method Using Thermography Under Non-steady State Heat Flow. Energy Procedia 2015, 83, 320-329. [CrossRef]

39. Aversa, P.; Palumbo, D.; Donatelli, A.; Tamborrino, R.; Ancona, F.; Galietti, U.; Luprano, V.A.M. Infrared thermography for the investigation of dynamic thermal behaviour of opaque building elements: Comparison between empty and filled with hemp fibres prototype walls. Energy Build. 2017, 152, 264-272. [CrossRef]

40. International Organization for Standardization. 2012. UNE EN ISO 10456:2012 Building Materials and Products—Hygrothermal Properties—Tabulated Design Values and Procedures for Determining Declared and Design Thermal Values; International Organization for Standardization: Geneva, Switzerland, 2012.

41. AVIO Systems. InfRec Analyzer Software. 2015. Available online: https://www.infrared.avio.co.jp/en/ support/thermo/download/ns9500lt-dl/index.html (accessed on 14 December 2020).

42. FLIR Systems. FLIR TOOLS+ Software. 2015. Available online: https://www.flir.com/products/flir-tools/ (accessed on 14 December 2020). 
43. Asdrubali, F.; D’Alessandro, F.; Baldinelli, G.; Bianchi, F. Evaluating in situ thermal transmittance of green buildings masonries: A case study. Case Stud. Constr. Mater. 2014, 1, 53-59. [CrossRef]

44. RESNET-Residential Energy Services Network. RESNET Interim Guideline for Thermographic Inspections of Buildings. Available online: http://www.resnet.us/standards/RESNET_IR_interim_guidelines.pdf (accessed on 20 October 2020).

Publisher's Note: MDPI stays neutral with regard to jurisdictional claims in published maps and institutional affiliations.

(C) 2020 by the authors. Licensee MDPI, Basel, Switzerland. This article is an open access article distributed under the terms and conditions of the Creative Commons Attribution (CC BY) license (http://creativecommons.org/licenses/by/4.0/). 